\title{
Sujeito, consumo \\ e solidariedade: as \\ ausências e presenças
}

Marilia Veríssimo Veronese

\section{Resumo}

Neste texto, problematiza-se a questão do consumo como categoria importante na produção cotidiana da vida. Intenta-se demonstrar que as formas de consumir bens materiais e imateriais são produto e produtoras de fluxos de subjetivação, geram modos de viver e de ser e, portanto, podem levar a formas mais (ou menos) solidárias de existência. No campo do consumo ético e solidário, discutir a questão das práticas de consumo é fundamental para compreender a produção e reprodução da vida social, na direção de modos mais solidários de viver. Além de uma revisão da literatura das ciências sociais sobre o consumo, utilizase 0 referencial da sociologia das ausências e emergências, de autoria de Boaventura de Sousa Santos. Procuramos assim trazer ao debate uma reflexão que inclua o problema da subjetividade.

Palavras-chave

Consumo. Subjetividade. Solidariedade.

Sociologia das ausências.

\section{Marilia Veríssimo Veronese I mariliav@unisinos.br}

Mestre e doutora em psicologia pela Pontifícia Universidade Católica do Rio Grande do Sul - PUCRS. Docente e pesquisadora do Programa de Pós-Graduação em Ciências Sociais da Universidade do Vale do Rio dos Sinos - UNISINOS.

\section{Sujeito desejante e práticas de consumo}

Nós, humanos, somos seres de desejo e pulsão (CHANLAT, 1996); somos faltosos, e via de regra, queremos muitas coisas. Almejamos, desejamos, perseguimos, enfim, vivemos sempre com algum motivo para a ação, ou sob o efeito de alguma coisa que nos desloca, nos faz produzir ativamente a vida e seus sentidos. Na ausência desses fatores que nos movem, eventualmente sobrevém algum problema, como sentimentos de estagnação na vida, depressões etc. É como se precisássemos, mesmo, ter sempre algo a buscar.

Queremos amor, aceitação, prazer, bens simbólicos que tragam reconhecimento afetivo e social, enfim, tudo que nos proporcione gratificação. Algumas dessas coisas, sensações, vivências e objetos, queremos conscientemente; reconhecendo ou não para os outros, sabemos, contudo, o que estamos buscando.

Mas certamente alguns desejos e necessidades são mantidos - pelo mecanismo que a psicanálise denomina de repressão - na área de nossa cognição que não alcançamos plenamente, 0 
inconsciente. Afinal, temos as exigências da cultura internalizadas, que numa linguagem psicanalítica clássica seriam as instâncias egóica e supergóica. Alguns desejos, então, seriam inconfessáveis até para nós mesmos, seriam inconscientes, motivando ações que nem nós compreendemos muito bem.

Um aspecto interessante e do qual eu gostaria de partir nesta reflexão sobre formas de consumir e produção do cotidiano, é que hoje a cultura ocidental contemporânea está quase que desdenhando do mecanismo de repressão. Ele não é mais tão necessário no campo do desejo. Realmente, esse mecanismo de defesa já viu tempos melhores para sua utilização. Por exemplo, na Viena do século XIX, onde a psicanálise nasceu, ou mesmo no Brasil, na primeira metade do século XX, especialmente se o sujeito em questão fosse mulher... 0 que seria dela sem a capacidade de reprimir tantos desejos impossíveis sequer de confessar? 0 que dizer de realizá-los? A repressão era, então, a única forma de (sobre)viver em tais contextos.

Hoje, contudo, é válido querer mais, querer vorazmente, buscar o prazer, "mimar-se", permitir-se as delícias da sociedade de consumo; é até um acinte não querer, não buscar avidamente. 0 capitalismo globalizado contemporâneo não lembra mais, nem um pouco, a ética protestante. Nas camadas médias da sociedade, negar-se a gastar fortunas em cirurgias plásticas completamente desnecessárias já é quase visto com surpresa, interpretado como "descuido" do próprio corpo. Afinal, a idade deve desaparecer; todos devem manter-se jovens, custe o que custar. $\mathrm{E}$ isto, de preferência, deve gerar mercados consumidores milionários. Jurandir Freire Costa (2004) tem tratado dessa questão de forma brilhante, oferecendo uma análise qualificada dos processos contemporâneos de corpolatria e das bio-identidades ditadas pela medicina - ao propor intervenções modelares sobre o corpo, seu formato, sua fertilidade etc. -, e por alguns agentes midiáticos, que colocam modelos de perfeição física como produtos a serem consumidos.

As formas de consumo assumem um formato peculiar, pois os objetos de consumo, materiais e imateriais, corporais e mentais, atormentam o sujeito que quer muito, deseja muito, anseia deveras, embora não seja humanamente possível obter tantas gratificações (umas reais, outras ilusórias, ainda que psiquicamente reais). Então o consumo, dependendo do contexto, quando se torna uma ideologia de consumo cuja manifestação nas pessoas é o tão criticado consumismo -, pode ser o tormento do sujeito. Se ele não puder consumir o que deseja, sentirse-á excluído do mundo a que almeja pertencer, e julgar-se-á profundamente infeliz. Sua própria identidade está ligada ao consumo; em lugar do "penso, $\log 0$ existo", seria o "consumo, logo existo". Consumir produtos necessários, produtos "supérfluos", produtos que demarcam identidades; desde roupas, móveis, carros, 
sabonetes, alimentos, imagens, discursos e eventualmente 0 próprio corpo, consumido como prêmio, com possibilidades eróticas ou narcísicas que assumem um sentido novo na contemporaneidade.

Pessoas que colocam silicone em várias partes do corpo estão, também, consumindo sua imagem, além de contarem com o corpo como um "produto" considerado excelente no "mercado" social ou amoroso (alguns chamam a isso de mercadorização de todas as instâncias da vida). 0 que antes era parte de algo proibido, escondido, inconfessável, fortemente reprimido - 0 corpo e seus desejos -, é hoje produto a ser amplamente exposto da forma mais atrativa possível.

Certamente, processos conscientes e inconscientes de grande complexidade estão na base dessas escolhas e, portanto, do consumo em geral.

Meu argumento é que as teorias de escolha racional, calcadas na noção de utilitarismo, são parciais e limitadas, numa análise psicossocial do consumo. A teoria da escolha racional é definida como a teoria social que se propõe a explicar o comportamento social e político assumindo que as pessoas agem racionalmente (BAERT, 1997). 0 problema, nesse caso, é que estaremos falando de indivíduos, não de sujeitos: 0 indivíduo de Descartes é plenamente racional; o sujeito relacional, não. Este se constitui a partir das relações que estabelece, através de um processo singular de apreensão do mundo e criação de sentidos que orientam ações e percepções. É 0 ser desejante, faltoso e buscador que aludi no início desta seção, que não se constrói sozinho, mas sim em relação. A alteridade é a condição da própria constituição do eu psíquico e da identidade do sujeito, sendo o psiquismo um sistema transindividual.

A tradição sociológica das teorizações sobre identidade está ligada ao conceito de self (ou si-mesmo) constituído a partir da linguagem e da comunicação. Para Geroge Herbert Mead (1963) o self é uma estrutura social, sendo impossível concebê-lo fora das interações desse âmbito. É importante frisar que, em seu entendimento, 0 ato comunicativo é a unidade básica de análise das ciências sociais. Segundo Farr (1998), Herbert Blumer, após a morte de Mead e a partir do trabalho deste, cunha o termo "interacionismo simbólico", concepção na qual a identidade não seria fixa, mas sujeita às transformações ocorridas ao longo do processo de interação do indivíduo com os seus grupos sociais e demais agentes socializadores.

0 campo do sentido, que Rey (2003) sublinha como o nó da subjetividade, é formado pela multiplicidade de sentidos produzidos no social, apropriados por pessoas, grupos, comunidades e sociedades. Esse autor define sentido subjetivo como a unidade inseparável dos processos simbólicos e das emoções num mesmo sistema. Para ele, o sujeito é efeito e não causa da ordem simbólica, pois tudo que preexiste a ele demarca o seu lugar e a sua apropriação do contexto. 
Sintetizando, estou entendendo o ser humano como um sujeito que pode agir intencionalmente, refletir, mas que também não tem acesso completo às poderosas forças que vão atingilo no decorrer da sua existência; portanto, um sujeito que possui uma consciência, mas que é também precarizado, desejante, faltoso, desamparado no sentido psicanalítico (FREUD, 1996). Portador de uma história singular tecida nas relações que estabeleceu, todo o seu acesso ao mundo é mediado pela alteridade, por isso ele ou ela é relacional por excelência. 0 espelho da alteridade lhe constitui a identidade que 0 caracteriza e a diferença que o singulariza.

A ação social, desse modo, não poderá ser unicamente analisada na perspectiva da escolha racional. As práticas de consumo, como as demais práticas sociais, vão estar sujeitas a condições de ambigüidade, contradição e ambivalência, a exemplo do próprio sujeito e do mundo social do qual é produto e produtor. Desejos, crenças, representações e semantização singular do social estarão por trás das escolhas de consumo. Não somos meras vítimas das semioses publicitárias, mas também não podemos cometer a ingenuidade de julgar-mo-nos imunes a elas.

Aqui cabe uma menção ao conceito de polifasia cognitiva, introduzido por Serge Moscovici (2003) na sua teorização sobre representações sociais. 0 conceito exprime a idéia de que diferentes lógicas e racionalidades estão presentes num mesmo sujeito. Por exemplo, ser cientista e freqüentar terreiros de umbanda é algo aparentemente contraditório, mas as pessoas fazem essas coisas, o que prova que são subjetivadas por processos também contraditórios, e que motivações nem sempre conscientes estão por trás de suas ações (JOVCHELOVITCH, 2004).

Passemos agora a revisitar algumas teorizações sobre consumo nas ciências sociais.

\section{Visões sobre 0 consumo}

Nas ciências sociais, desde Marx, existe a problematização do consumo; sua análise criticava justamente a relação de alienaçãofetichismo presente no consumo dos produtos do capitalismo. E o fato, em especial numa perspectiva contemporânea, é que não se consomem somente produtos materiais, mas também signos, representações, enfim, intensa produção simbólica (que envolve o corpo humano talvez como nunca antes).

0 consumo é definido por Canclini $(1999$, p. 77) como: "0 conjunto de processos socioculturais nos quais se realizam a apropriação e os usos dos produtos". Para esse autor, o consumo ocorre no campo do simbólico, um campo no sentido de Bourdieu (1983). Para este último, campos sociais são: "[...] espaços estruturados de posições cujas propriedades dependem das posições nestes espaços, podendo ser analisadas independentemente das características de seus ocupantes [...]. (p. 89). Nesse sentido, significa que 
os sujeitos se relacionam em um espaço de forças estruturado, que molda a capacidade de ação e de decisão de quem dele participa; essa abordagem questionou vivamente a noção de autonomia ligada ao sujeito psíquico em moldes cartesianos.

A abordagem de Canclini densifica a questão, pois embora critique 0 aspecto de que no capitalismo houve uma espécie de "troca" da cidadania pelo consumo, trata o consumo como elemento central na cultura, algo em permanente transformação, a partir das relações estabelecidas entre os grupos sociais nos campos onde interagem.

Jean Baudrillard (1991) referiu-se a uma "sociedade de consumo", e Mike Featherstone (1995) utilizou o termo "cultura de consumo". Os autores contemporâneos destacam o fato de que 0 consumo assume uma importância cultural central, superando, em alguns casos, a dimensão econômica dos produtos.

Para Mancebo et al. (2002), também calcados nas teorizações de Pierre Bourdieu, o acúmulo de bens de consumo específico irá atestar 0 bom gosto e a distinção de quem os possui e se constituem num verdadeiro capital cultural ou simbólico, que não se apresenta em "qualquer" cidadão. 0 conceito de habitus desenvolvido por Bourdieu (1983) remete às disposições (inconscientes ou não), a esquemas classificatórios, a preferências que o sujeito tem e que lhe asseguram a impressão de adequação e validade nos ambientes em que se relaciona e aos quais sente pertencer.
É bem conhecida, também, a crítica da Escola de Frankfurt à indústria cultural, à produção de ideologias várias que povoam 0 cotidiano e a vida dos sujeitos, compondo um universo de representações que constituem, em parte, o desejo e o inconsciente humanos. Seu argumento, que enfatiza o papel da cultura na reprodução do capitalismo, é razoável o suficiente para ser amplamente aceito, embora também tenha sido questionado; mas o problema central é o de determinar em que medida e de que formas isso acontece.

Segundo Barbosa (2004), na sociedade póstradicional, o consumo é a forma privilegiada de negociar identidade e status social, construídos a partir dos indivíduos. A identidade terá passado a ser uma função do consumo, ao invés do contrário?

Tendo presente a idéia que o consumo é, desde tempos imemoriais, necessário para a sobrevivência da espécie, é fascinante analisar como suas formas mudam, como a dimensão do simbólico - das representações sociais compartilhadas por um auditório que pode ser um grupo, comunidade, instituição, receptores das mídias - molda e constitui modos de consumir. Esses modos se expressam e concretizam no cotidiano desses indivíduos, grupos e comunidades.

Claro que há aspectos a considerar que impedem uma análise totalizante, com afirmações a serem generalizadas. Por exemplo, as práticas 
de consumo nas sociedades tradicionais ainda diferem em alguns pontos da sociedade ocidental capitalista; a sociedade indiana, por exemplo, tem prescrições religiosas que orientam o consumo em alguma medida. Em algumas sociedades orientais, na ausência de uma ideologia do amor romântico, a tarefa de escolher o cônjuge pode estar a cargo dos pais, bem como a maneira dos filhos vestirem-se, relacionarem-se etc. Nesse caso, a relação dos jovens com o consumo de bens e a maneira que vivenciam seus relacionamentos irá diferir significativamente daqueles que vivem em sociedades ocidentais, fortemente des-tradicionalizadas.

Para Barbosa (2004), pode-se viver numa sociedade de consumo, numa economia de mercado, mas a cultura e as tradições podem ter uma certa independência dessa esfera, não sendo o consumo utilizado "como a principal forma de reprodução e diferenciação social" (p. 9).

Contudo, nas sociedades capitalistas póstradicionais, o poder de consumo chega a determinar o grau de cidadania de que um sujeito possa desfrutar: com o primado das relações econômicas calcadas no capitalismo globalizado e regidas pelo Consenso de Washington, com a falência do estado de bem-estar, só desfruta plenamente da cidadania quem pode consumi-la, ou seja, pagar por saúde, educação, segurança, lazer etc. Aqui se configura uma abordagem do que seria a substituição do cidadão pelo consumidor, e da colonização do Estado pelo mercado; se a noção de cidadania, em alguma medida, remete a um Estado provedor, a noção de consumidor remete ao poder de consumo, no âmbito do mercado capitalista.

Segundo Santos (2001), basicamente, os traços do Consenso de Washington são os seguintes: as economias nacionais devem abrir-se ao mercado global e os preços locais devem ajustar-se a estes; a prioridade deve ser a economia de exportação e as políticas monetárias e fiscais devem ser orientadas para a redução da inflação, além da vigilância sobre a balança de pagamentos; o setor empresarial do Estado deve ser privatizado e os direitos de propriedade privada devem ser claros e invioláveis; deve ser garantida a mobilidade dos recursos, investimentos e lucros e a regulação estatal deve ser mínima, reduzindo-se 0 "peso" das políticas sociais do orçamento do Estado, além da exigida subordinação dos Estados nacionais às agências multilaterais do tipo Fundo Monetário Internacional ou Banco Mundial. Refere-se à emergência de uma classe capitalista transnacional, cuja principal forma institucional é a empresa multinacional.

Segundo alguns críticos desses dois séculos de capitalismo que resultaram no consenso entre os "vencedores" (economias ricas do Norte), dentre eles Zygmunt Bauman (2001), um certo tipo de consumo é ensinado e aprendido como forma cultural, é parte da produção de subjetividade capitalística $^{1}$, para manter garantido o lucro das 
corporações que, através do marketing, afirmam aos consumidores que eles estão "livres para consumir", sendo esse 0 sentido de liberdade veiculado. Para Bauman, sobre a desintegração da cidadania, fenômeno típico da modernidade líquida (2001, p. 46):

Se [...] a individualização anuncia problemas para a cidadania e para a política fundada na cidadania, é porque os cuidados e preocupações dos indivíduos enquanto indivíduos somente, enchem 0 espaço público até 0 topo, afirmando-se como seus únicos ocupantes legítimos e expulsando tudo o mais do discurso público. 0 público é colonizado pelo privado; 0 interesse público é reduzido à curiosidade sobre as vidas privadas de figuras públicas e a arte da vida pública é reduzida à exposição pública das questões privadas e a confissão de sentimentos privados (quanto mais íntimos melhor). As questões públicas que resistem a essa redução tornam-se quase incompreensíveis.

A crítica de Bauman é contundente, levantando contestações, que a rotulam como reducionista, portadora de certo saudosismo de um passado não muito bem definido, onde as coisas "seriam diferentes" (BARBOSA, 2004).

Pareceria insensato atribuir à cultura capitalista globalizada o monopólio de estabelecer 0 consumo de bens para demarcar territórios simbólicos, pertença, exclusão ou inclusão em grupos sociais etc., argumentam os críticos de Bauman. Afinal, culturas tradicionais também possuem práticas sociais onde roupa, as posses e outros demarcadores simbólicos determinam posições na sociedade. Mas o que me parece específico é a forma que a cultura ocidental globalizada reproduz as práticas de consumo ligadas a uma esfera imaterial, onde imagens - ou desejos de imagens -, são consumidas e subjetivam indivíduos e coletivos ao redor do planeta.

Consumo e produção são instâncias totalmente descoladas uma da outra, nesse contexto.

Quem, do cidadão médio, conhece 0 conceito de cadeia produtiva, ou preocupa-se em conhecer as características das cadeias que originam os produtos que consome? Aqui se evidencia a primeira grande ausência: a preocupação com as formas de produção daquilo que consumimos. Mesmo sem subscrevermo-nos a perspectivas como as de Bauman, radicalmente críticas da sociedade de consumo, até um tanto condenatórias desta última, parece impossível dizer-se neutro diante da prática de consumir produtos de empresas que ignoram completamente a responsabilidade social e ambiental diante dos trabalhadores e da comunidade. Esse é o mote da discussão que une cotidiano, consumo e economia solidária.

\section{Solidariedade e consumo}

Como estudiosa do trabalho autogestionário no contexto da economia solidária, acho por demais importante problematizar as práticas de consumo, tanto em nível teórico, como em uma espécie de etnografia do cotidiano do consumo. Isso seria, é claro, um projeto ambicioso. 0 fato é que precisamos ampliar nossas análises sobre consumo, até porque o comércio justo e os empreendimentos econômicos solidários dependem do consumo dos 
cidadãos de uma sociedade, da mesma forma que seus correlatos capitalistas.

Temos, no panorama contemporâneo, formas híbridas de consumo, alguns mesmo com motivações solidárias. Por esse motivo, acredito que estudos de caso, observações de certos grupos sociais e a análise de suas motivações para 0 consumo, poderiam elucidar alguns aspectos importantes para 0 campo da produção na economia solidária.

Esta última evoca um campo multiforme de iniciativas, hoje objeto de estudos comparativos (SINGER; SOUZA, 2000; FRANÇA FILHO, 2006) e de alguns intentos de sistematização teórica (CATTANI, 2003). 0 conceito abrange empresas de autogestão, cooperativas de prestação de serviços ou agropecuárias, variadas formas de organização associativa e um sem-número de grupos comunitários informais, além de programas direcionados ao setor, como o crédito rotativo, os bancos populares e as tecnologias sociais de incubação de empreendimentos. Essas iniciativas assumem em dose variável um caráter coletivo na gestão, na posse dos meios de produção pelos trabalhadores e no processo de trabalho, minimizando a presença de relações assalariadas e provocando envolvimento com problemas sociais e com questões da cidadania. As experiências variam, porque variam seus protagonistas, suas atividades e seus resultados. Sua expansão é registrada em diversos continentes, ao sul e ao norte (SANTOS; RODRIGUEZ, 2002), bem como suas conexões com novos movimentos sociais (MENDELL, 2003) e suas fragilidades e incertezas (LIMA, 2004; GAIGER, 2004; 2006).

Como princípios geradores de sua ética, estão os valores de boa convivência humana entre si e com 0 ambiente. Muitas experiências populares de produção econômica e de geração de renda, no Brasil e em outros países, estariam formando uma economia popular fundada na cooperação solidária e integrada à economia de mercado, segundo uma lógica não-mercantil (SINGER, 2002). Nela residiria uma das alternativas consistentes para os setores de baixa renda e as classes trabalhadoras, diante dos processos de empobrecimento e de desocupação estrutural que os atingem. As formas de trabalhar e consumir estariam conectadas não apenas à produção e distribuição de produtos e serviços, mas à criação e re-criação da vida em sociedade.

As cooperativas de produção e consumo têm protagonizado alternativas às formas hegemônicas. E, no dizer de Paul Singer (2002), no laboratório da história, o único método disponível é o da tentativa e erro. E é justamente dessa forma que as experiências têm evoluído. Daí suas muitas dificuldades e precariedades, especialmente em países da periferia do sistema mundial, que já ocupam um lugar específico - e subalterno - na divisão social do trabalho (VERONESE, 2007). 
Gaiger (2004) cunhou o termo empreendimento econômico solidário, que define as organizações pautadas pelo solidarismo e autogestão, por um lado, e viabilidade econômica, por outro. Segundo dados do mapeamento nacional da economia solidária realizado pela Secretaria Nacional de Economia Solidária (SENAES), há cerca de 22.000 empreendimentos econômicos solidários no Brasil. A maior concentração deles é na região norte-nordeste, embora apareçam expressivamente também nas regiões sudeste e sul (SENAES, 2006). A maioria surgiu após 1990 e, segundo os trabalhadores, as razões de sua criação constituem, nesta ordem: a) alternativa ao desemprego; b) complemento de renda; c) aumento de ganhos; d) possibilidade da gestão coletiva da atividade; e) condição para acesso a crédito.

Essa realidade complexa e multifacetada vem sendo objeto de análise de estudiosos de diversos campos: Sociologia, Economia, Psicologia, Antropologia, Comunicação etc. E, mais do que nunca, tornam-se importantes os estudos relacionados a este elemento fundamental da trama da vida econômica e social: o consumo.

Para Mance (2003), existem algumas categorias que constituem uma tipologia de consumo, que ele apresenta como: alienado, compulsório, para o bem-viver e solidário. Do primeiro tipo, totalmente dominado pela influência das semioses publicitárias, até 0 último, praticado em prol do bem-estar coletivo, com preferência por produtos gerados de forma solidária (sem exploração do trabalho) e responsável ambientalmente (ecológicos, que não degradaram a natureza em seu processo produtivo), temos uma graduação de tipos de consumo.

Segundo Zerbini (documento eletrônico), 0 consumo ético é aquele praticado por um ator político responsável, que utiliza suas escolhas para intervir positivamente na realidade social e ambiental que o cerca; e o comércio justo é um fluxo comercial diferenciado, que resulta em alguma forma de empoderamento dos trabalhadores e produtores assalariados, agricultores familiares, indígenas, quilombolas, extrativistas e campesinos em desvantagem ou marginalizados pelo sistema convencional de relações comerciais.

Para Barciotte (2002), o consumo ético é a capacidade de cada pessoa ou instituição, pública ou privada, de escolher serviços e produtos que contribuam, de forma ética e de fato, para a melhoria de vida de cada um, da sociedade e do ambiente.

0 fato que complica um pouco a classificação de Mance (2003) e as definições de consumo responsável e solidário, é que coexistem, na maioria de nós, todas essas formas de consumir, hibridizando-se de forma por vezes contraditória e subordinada a muitas lógicas diversas, elas próprias contraditórias. $0 u$ seja, não fazemos escolhas somente em nível racional, do cogito "puro". Supondo que eu tenha alguma razão quanto à natureza híbrida e ambivalente das formas de consumo dos cidadãos conscientes, 
estes últimos serão interpelados tanto pelas mensagens oriundas de campos onde a crítica ao consumo alienado prevalece, quanto de campos onde o status gerado pela posse de determinados atributos ou objetos é o determinante dos motivos para a ação que referi no início do texto. Não esquecendo, também, da condição de polifasia cognitiva do sujeito humano.

Então, vimos que o conteúdo simbólico produzido na sociedade, as formas simbólicas (THOMPSON, 2002), como um amplo espectro de ações e falas, imagens e textos, circulam e são apropriadas de formas diversas por diferentes sujeitos em contextos distintos. Não é totalmente consciente, portanto, a absorção de tudo aquilo que irá determinar o comportamento do sujeito como consumidor. Por isso, eu defendo o incremento da pluralidade de formas simbólicas circulantes nos ambientes institucionais, grupais, comunitários, midiáticos e familiares, aumentando a freqüência daquelas que despertem as consciências para a necessidade do consumo ético, pelo menos como parte de nossas escolhas diárias. Uma segunda grande ausência que ressalto, nos espaços midiáticos, é a preocupação com os aspectos éticos do consumo, onde a presença massiva dos interesses financeiros superam qualquer outro possível discurso.

Esse aspecto, justamente, é que me parece procedente nas críticas de Bauman (2001) ao capitalismo contemporâneo e a participação da mídia na sua reprodução. Há autores que defendem que, contrariamente às teses de
Bauman, hoje já existem muitas tendências na direção oposta àquela que 0 autor "condena", como, por exemplo, os dispositivos institucionais alternativos dirigidos às questões do social, do tipo ONGs, redes de resistência globais bem articuladas, comércio justo, economia solidária etc., o que comprovaria que a análise "condenatória" de Bauman está equivocada (BARBOSA, 2004). Se há razão nisso, provavelmente o há na mesma proporção que há razão nas "condenações" de Bauman: lembremos que uma parcela diminuta da sociedade (de modo algum a sua maioria, é bom frisar) participa dessas iniciativas consideradas emancipatórias, sendo que uma grande parte dela (a maioria, certamente) sofre diretamente os efeitos da mídia de massa e suas mensagens publicitárias. As mídias são poderosas difusoras de representações e práticas, mas também elas são espaços contraditórios, o que definitivamente complica ainda mais nossas análises.

Segundo Appadurai (1999), a mídia em sua versão eletrônica é um dos principais fatores que demarcam o mundo pós-eletrônico. A imaginação e os desejos que ela produz passam a ser não só do indivíduo romântico ou do espaço da arte, como na modernidade, mas sim um fenômeno de massa. Essa é a subjetividade produzida pela rápida circulação de informações e pela globalização de alguns localismos, a exemplo do McDonald's, cultura do fast-food etc. 0 autor afirma que é através dessa imaginação - circulação de formas 
simbólicas, de espaços simbólicos midiáticos que os cidadãos são disciplinados e controlados pelos interesses dominantes de mercados e Estados (ou outros agentes); mas é também por essa via que se desenvolvem sistemas coletivos de dissidência e novos grafismos da vida coletiva. $\mathrm{Ou}$ seja, existem alternativas dentro dos sistemas de dominação midiáticos que criam possibilidades de transformação social. A cultura de massa seria então, a um só tempo, o lugar dos consensos e 0 lugar da resistência e da luta contra a conformidade.

Nesse contexto, poder-se-ia começar por aumentar a pluralidade de discursos na esfera pública e na publicidade de massa, que invade a esfera privada, publicizando-a. Aumentando a pluralidade de alternativas em termos de veículos de subjetivação, pode-se esperar um aumento de perspectivas críticas, inovadoras ou que questionem o satus quo, o suficiente para garantir uma tensão dialética entre regulação e emancipação social (SANTOS, 2000). 0 mundo da produção e do consumo solidários, aqui, pode significar algo importante nessa perspectiva.

Pluralidade e diversidade são coisas desejáveis; hoje não parece haver dúvidas disso entre os que anseiam por um mundo mais justo. Não queremos mais a sociedade planificada do socialismo, onde todos seriam iguais e as ambições humanas seriam extintas em prol do novo homem socialista, nem que fosse preciso utilizar o "paredão" no processo de livrar-se das incomôdas subjetividades rebeldes, que teimassem em não reconhecer o socialismo como a melhor (ou única) opção... Contudo, no questionamento dos pressupostos socialistas clássicos (onde havia uma forma de emancipação, levada a cabo por um ator social privilegiado, a classe operária), fica-nos uma espécie de vácuo de perspectivas de ação, o que no melhor dos casos leva justamente à busca de alternativas emancipatórias entre a pluralidade do mundo social. Na pior das hipóteses, o vácuo conduz ao niilismo, ao cinismo e ao consumo totalmente alienado. Ou ainda, no mesmo sujeito, ora a um comportamento, ora a outro. Como teorizar uma situação tão complexa e contraditória?

Nesse ponto, peço auxílio teórico a Boaventura de Sousa Santos (2000; 2004), pois esse autor professa a veemente necessidade de produzir-se uma teoria crítica pós-moderna, entendendo este último conceito como a tentativa de superação dos problemas modernos, para os quais não existem soluções modernas. As soluções modernas do demo-socialismo (políticas emancipatórias obtidas por meios parlamentares legais, gradualmente conseguidas, ou social-democracia) ou do demo-liberalismo (democracia liberal sem a tendência aos Estados-providência, sem concessões sociais distributivas), bem como a alternativa radical da revolução socialista não deram conta de criar uma sociedade justa, com eqüidade social, pelo menos a longo prazo e globalmente. Portanto, não existem soluções modernas para os problemas modernos. 
É justamente aí que entra a concepção da sociedade plural e diversa, na qual diferentes formas de emancipação social sejam válidas: quem quiser reabilitar essas perspectivas desacreditadas, teria todo o direito de tentar fazê-lo. Quem quiser viver sob a égide de outras alternativas, teria de ter espaço para produzilas e fazê-las emergirem, transformando em presenças as ausências do mundo da forma mais factível e criativa possível, no seu contexto.

Uma das formas identificadas de alternativas no campo da produção econômica e do consumo seria justamente a economia solidária, por ser regida na direção de uma lógica oposta à da troca desigual, criando espaços de sociabilidade, produção e comércio em pequena escala, comunitários, buscando a auto-sustentabilidade e a cooperação/ participação interpessoal e intercomunitária.

Muitas pessoas, grupos, instituições e comunidades estão descobrindo que consumir produtos da economia solidária pode ser interessante sob vários aspectos. Primeiro, é algo relativamente simples, com 0 crescimento das feiras e pontos de venda desses produtos, o que facilita seu consumo no cotidiano; segundo, a qualidade vem aumentando, conforme aumenta 0 interesse e 0 fomento aos empreendimentos econômicos solidários; terceiro, o impacto social é significativo, uma vez que tende a fortalecer as cadeias produtivas solidárias, solidificando também o papel dos que protagonizam o movimento da economia solidária, geralmente os sujeitos mais vitimizados pelo flagelo da desigualdade social. Assim, quem busca modos mais solidários de existir, sem ter de doar-se a um movimento 24 horas por dia ou pegar em armas, ou ainda alguma outra opção dramática, tem no consumo solidário e na consciência ambiental que ele tende a gerar uma opção viável de prática social emancipatória.

\section{A emergência de formas emancipatórias de subjetivação apesar das desigualdades}

0 Brasil caracteriza-se pela persistência das desigualdades; ao perdurarem, elas penetram nos valores e incorporam-se aos padrões culturais, formando representações que geram práticas sociais excludentes. 0 poder instituinte das desigualdades aparece então nas formas latentes de segregação racial/étnica, nas discriminações de gênero e na naturalidade com que se aceita a brutal distância social entre os brasileiros. São arrastados à condição de ausência milhões de cidadãos, "incapazes" de integrarem-se aos mercados produtivos e de atenderem às exigências das empresas capitalistas. Os ausentes ou inexistentes são os que ficam "fora do jogo" do consumo capitalista, e essa ausência é notada por diversos autores ao discutir a questão do consumo, a exemplo de Mancebo et al (2002, p. 330).

[...] 0 capitalismo, ao criar acessos cada vez mais amplos e diversificados, também faz valer as suas "regras" em um maior número de domínios, em campos mais moleculares e mais íntimos, de modo que o fato de comportar uma grande quantidade de modelos de realização, não exclui a submissão ao seu axioma central: 
mais produtividade e mais consumo. [...] enquanto para alguns se trata da análise do porquê consomem tanto, para "mais de um bilhão de pessoas consumir mais é uma questão de vida ou morte e um direito básico - 0 direito de libertar-se da carência" (Gordimer, 2000). Em outros termos, há muitos que ficam fora deste universo de estudo denominado consumo, o que evidentemente tem grande efeito tanto sobre os que ficam de fora, quanto sobre os que estão dentro.

Novamente é de grande valia a utilização das categorias propostas por Santos (2002; 2003; 2004), a sociologia das ausências e emergências e 0 procedimento de tradução. Esses três procedimentos sociológicos se explicam da seguinte forma: a descoberta do que é produzido para estar ausente do mundo da globalização neoliberal é a sociologia das ausências, uma espécie de escavação do presente; a possibilidade de novos futuros possíveis a partir dessas experiências agora tornadas presentes, é a sociologia das emergências; e a criação de inteligibilidade mútua entre as diversas experiências é a teoria da tradução, ou melhor, o procedimento de tradução, já que se trata de uma prática.

Se 0 aspecto mais promissor da sociedade contemporânea traz a tônica da diversidade, novas e múltiplas possibilidades de existência emergem e tornam-se presenças, a exemplo do movimento social da economia solidária e de tantos outros movimentos sociais emancipatórios. Conferir credibilidade às diversas alternativas, no plural, seria o objetivo da prática da sociologia das ausências. Numa versão psicossocial, a ser incorporada à psicologia social, a psicologia das ausências é aquela que procura conhecer, validar e creditar alternativas em termos de modos de ser, viver, amar, trabalhar, sentir, parecer, nutrir, consumir... diferentes dos tradicionais, hegemônicos ou considerados como únicos válidos.

Enquanto a sociologia das ausências se move no campo das experiências sociais, a sociologia das emergências move-se no campo das expectativas sociais. Ou seja, uma se refere ao presente, outra ao futuro, às possibilidades que as práticas presentes produzirão.

A questão é reconhecer que cabem muitas totalidades no real, todas necessariamente parciais. A esta altura, surge 0 trabalho de tradução no lugar da teoria geral, que pretenda mostrar o caminho da emancipação social. A tradução é o procedimento que permite criar a inteligibilidade recíproca entre as experiências e perspectivas diversas do mundo. Se os atores do movimento associativo e solidário na esfera da produção não puderem entender que a causa do movimento negro, dos gays, da luta pela terra ou das mulheres oprimidas situa-se igualmente no campo da resistência ao neo-conservadorismo, colonialismo e patriarcalismo, enfraquecerão 0 campo de lutas por mudança social como um todo. Por isso, é necessário que os agentes traduzam, uns para os outros, as suas preocupações isomórficas no que se refere à transformação do instituído, expandindo e pluralizando as redes solidárias. 
A tradução entre saberes assume a forma da hermenêutica diatópica. Essa forma de hermenêutica consiste no trabalho de interpretação entre duas ou mais culturas com vistas a identificar preocupações isomórficas entre elas. Os topoi ou lugares de produção de saberes, discursos e práticas podem hibridizarse sem perder suas características e sua riqueza conceitual e prática. Todas as culturas são incompletas e podem se enriquecer com o diálogo com outras, no momento em que é reconhecida a impossibilidade da completude cultural. Entende-se que cada grupo social, ou mesmo cada sujeito individual traz a sua cultura própria, então a troca e a comunicabilidade entre sujeitos aumenta sua completude, a riqueza de sua existência; já que os sujeitos constroem realidades simbólicas de modo a orientar suas ações e práticas, quanto mais plurais forem as referências de que dispuserem nessas mediações, mais ricas aquelas serão. Por formas emancipatórias de subjetivação eu entendo todo o movimento que nos levar a alternativas solidárias de vida.

Acredito que solidariedade não é possível sem inteligibilidade e sem credibilidade. Estas podem ser geradas justamente através da ação comunicativa envolvida no procedimento de tradução. Gerar cumplicidades positivas e relações de reciprocidade, na descoberta de convergências antes não identificadas, é um processo que depende dos sujeitos envolvidos na ação.
Outro ponto a ressaltar é a importância da criação de redes, para aumentar o grau de participação, por parte dos cidadãos comuns, nas lutas por cidadania e igualdade na diferença, nas quais se inclui a militância pelo consumo ético. Algo que corrobora a necessidade de procedimentos de tradução, é que as redes não são formadas somente por sujeitos "angélicos", ou 100\% solidários, ou por organizações da autêntica economia solidária; são formadas entre elas e mais uma infinidade de tipos de pessoas e organizações, uma miríade composta por empresas capitalistas, associações de diversos tipos e portes, conselhos populares, instâncias governamentais etc., possivelmente bastante refratárias a um entendimento mútuo. É preciso, então, criar inteligibilidade entre elas, fortalecer as cumplicidades e os elos de identificação, respeitando as diferenças.

Acredito que seja somente na forma de rede que os empreendimentos econômicos solidários podem não somente se fortalecer enquanto tal, mas fortalecer o modo de vida e de consumo que eles próprios representam. Ampliar a rede é cooptar, entre os cidadãos comuns, usuários de produtos solidários, transformando o cotidiano e suas práticas de consumo, ou seja, transformando 0 próprio senso comum. Santos (2000) coloca que 0 objetivo do conhecimento científico é transformarse num novo senso comum, mais inclusivo, solidário, participativo e reencantado. Para isso acontecer no nível das práticas de consumo, é necessário que a economia solidária mostre-se inteligível enquanto alternativa qualificada. 
Partindo do pressuposto da incompletude das culturas e alternativas, elas sempre podem ser enriquecidas com elementos umas das outras. Justamente por isto é que 0 viver, 0 trabalhar, o consumir, 0 amar e 0 relacionar-se para uma sociedade mais solidária pode ser reinventado não como ruptura total, mas como reconstrução em cima de um cabedal de saberes que a humanidade já produziu, mas ainda não traduziu mais amplamente. Espera-se que as ciências sociais em geral possam contribuir para ampliar a tradução como processo social transformador.

\section{Referências bibliográficas}

APPADURAI, Arjun. Globalization and the research imagination. International Social Science, n. 160, p. 229-238, 1999.

\section{ARRUDA, Marcos. A cultura da socioeconomia solidária. Disponível em: <www.rau.edu.uy/ universidad/extension/proasoc/refbiblio/socioecon. pdf>. Acesso em: 20 mar. 2008.}

BARBOSA, Lívia. Sociedade de consumo. Rio de Janeiro: Jorge Zahar, 2004.

\section{BARCIOTTE, Maria Lucia. A importância da} educação para o consumo responsável. Rio de Janeiro: Nova Fronteira, 2002.

BAUDRILLARD, Jean. A sociedade de consumo. Lisboa: 70, 1991.

BAERT, Patrick. Algumas limitações das explicações da escolha racional na Ciência Política e na Sociologia. Revista brasileira de Ciências Sociais [online]. v. 12, n. 35, 1997. Disponível em: Disponível em: <http:// www.scielo.com.br>. Acesso em: 12 mar. 2007.

BAUMAN, Zigmunt. Modernidade líquida. Rio de Janeiro: Jorge Zahar, 2001.
BOURDIEU, Pierre. Questões de sociologia. Rio de Janeiro: Marco Zero, 1983.

\section{CANCLINI, Nestor. Consumidores e cidadãos:} conflitos multiculturais da globalização. Rio de Janeiro: UFRJ, 1999.

CATTANI, Antonio David. (org.) A Outra economia. Porto Alegre: Veraz, 2003.

CHANLAT, Jean François. (org.) 0 indivíduo na organização: dimensões esquecidas. São Paulo: Atlas, 1996.

COSTA, Jurandir Freire. 0 vestígio e a aura: corpo e consumo na moral do espetáculo. Rio de Janeiro: Objetiva, 2004.

FARR, Robert. Raízes da psicologia social. Petrópolis: Vozes, 2008.

FEATHERSTONE, Mike. Cultura de consumo e pós-modernismo. Rio de Janeiro: Guanabara Koogan, 1995.

FRANÇA FILHO, Genauto. (org.) Ação pública e economia solidária: uma perspectiva internacional. Porto Alegre: UFRGS, 2006.

FREUD, Sigmund. Obras completas. Rio de Janeiro: Imago, 1996.

GAIGER, Luiz Inácio. (org.) Sentidos e experiências da economia solidária no Brasil. Porto Alegre: UFRGS, 2004.

GAIGER, Luiz Inácio. A racionalidade dos formatos produtivos autogestionários. Sociedade \& estado, Brasília, v. 21, n. 2, 2006. Disponível em: <http://www. scielo.br/scielo.php?script=sci_arttext\&pid=S010269922006000200009\&lng=pt\&nrm=iso $>$. Acesso em: 17 set. 2007.

\section{GORDIMER, Nadine. A face humana da} globalização. Folha de São Paulo, Caderno Mais, p. 6-8, 20 fev. 2000. 
GUATTARI, Felix. Caosmose: um novo paradigma estético. Rio de Janeiro: 34, 1992.

JOVCHELOVITCH, Sandra. Psicologia social, saber, comunidade e cultura. Psicologia \& Sociedade, v. 16, n. 2, p. 20-31, 2004.

LIMA, Jacob Carlos. 0 trabalho autogestionário em cooperativas de produção; o paradigma revisitado.

Revista Brasileira de Ciências Sociais, v. 19, n. 56, p. 45-62, 2004.

MANCE, Euclides. Redes de colaboração solidária - Aspectos econômicos-filosóficos: complexidade e libertação. Petrópolis: Vozes, 2002.

MANCE, Euclides. Cadeias produtivas solidárias. In: Cattani, A. D. (org.) A outra economia. Porto Alegre: Veraz, 2003, p. 26-28.

MANCEBO, Deise.; OLIVEIRA, Dayse Marie; FONSECA, Jorge Guilherme Teixeira. Consumo e subjetividade: trajetórias teóricas. Estudos de Psicologia (Natal), v. 7, n. 2, p. 325-332, 2002.

MEAD, George Herbert. Mind, self and society. Paris: PUF, 1963.

MENDELL, Marguerite. La aparición de movimientos sociales internacionales y la economía social y solidaria. Économie et Solidarités, revue du CIRIEC, Canada, n. especial, p. 19-29, 2003.

MOSCOVICI, Serge. Representações sociais Investigações em psicologia social. Petrópolis: Vozes, $7^{\mathrm{a}}$ edição, 2003.

REY, Fernando Gonzalez. Sujeito e subjetividade. São Paulo: Thomson Learning, 2003.

SANTOS, Boaventura de Sousa. A crítica da razão indolente: contra o desperdício da experiência. Porto: Afrontamento, 2000. (org.) Globalização: fatalidade ou utopia?

Porto: Afrontamento, 2001. Para uma sociologia das ausências e uma sociologia das emergências. Revista Crítica de

Ciências Sociais, n. 63, p. 237-280, 2002.

Poderá o direito ser emancipatório? Revista

Crítica de Ciências Sociais, n. 65, p. 3-76, 2003. (org.) Conhecimento Prudente para uma

Vida Decente: "Um Discurso sobre as Ciências" Revisitado. São Paulo: Cortez, 2004. . ; RODRIGUEZ, Cesar. Introdução: para ampliar o cânone da produção. In: Santos, B. S. (org.) Produzir para viver: os caminhos da produção não-capitalista. Rio de Janeiro: Civilização brasileira, 2002. p. 23-78.

\section{SENAES (2006). Atlas da economia solidária no}

Brasil. Disponível em: <www.mte.gov.br/empregador/ economiasolidaria/conteudo/ATLAS_PARTE_1pdf> Acesso em: 03 dez. 2006.

SINGER, Paul. Introdução à economia solidária. São Paulo: Perseu Abramo, 2002. ; SOUZA, André Ricardo. (orgs.) A economia solidária no Brasil: a autogestão como resposta ao desemprego. São Paulo: Contexto, 2000.

THOMPSON, John. Ideologia e cultura moderna: teoria social crítica na era dos meios de comunicação de massa. Petrópolis: Vozes, 2002.

VERONESE, Marília Veríssimo. Psicologia social e economia solidária. São Paulo: Idéias \& Letras, 2007.

ZERBINI, Francisco. A cadeia produtiva do comércio ético e solidário e o empoderamento dos empreendimentos locais: relatório. Disponível em: <www.instituokairos.org/projetos/oficina_olinda.pdf>. Acesso em: 20 mar. 2008. 
Subject, consumption and solidarity: absences and presences

\section{Abstract}

This text discusses the issue of consumption as an important category in everyday life production. One tries to show that the means of consuming material and immaterial goods are product and producers of subjectification flows, that they create living and being standards and may therefore lead to more (or less) solidary existence ways. In the field of ethical and solidary consumption, discussing the matter of consumption practices is fundamental to understand the production and reproduction of social life towards more solidary ways of living. Besides a review of the literature of social sciences on consumption, we use as reference Boaventura de Sousa Santos's sociology of absences and emergences. So we try to bring to debate some reflection including the issue of subjectivity.

\section{Keywords}

Consumption. Subjectivity. Solidarity. Sociology of absences.

\section{Sujeto, consumo y solidaridad: las ausencias y presencias}

\section{Resumen}

En este texto se problematiza la cuestión del consumo como categoría importante en la producción cotidiana de la vida. Se intenta demostrar que las formas de consumir bienes materiales e inmateriales son producto y productoras de flujos de subjetivación, generan modos de vivir y de ser y, por lo tanto, pueden llevar a formas más o menos solidarias de existencia. En el campo del consumo ético y solidario, discutir la cuestión de las prácticas de consumo es fundamental para comprender la producción y reproducción de la vida social, en la dirección de modos más solidarios de vivir. Además de una revisión de la literatura de las ciencias sociales sobre el consumo, se utiliza el referencial de la sociología de las ausencias y emergencias de autoría de Boaventura de Sousa Santos. Así, se procura traer al debate una reflexión que incluya el problema de la subjetividad.

\section{Palabras clave}

Consumo. Subjetividad. Solidariedad.

Sociología de las ausencias. 


\section{Expediente}

A revista E-Compós é a publicação científica em formato eletrônico da Associação Nacional dos Programas de Pós-Graduação em Comunicação (Compós). Lançada em 2004, tem como principal finalidade difundir a produção acadêmica de pesquisadores da área de Comunicação, inseridos em instituições do Brasil e do exterior.
E-COMPÓS I www.e-compos.org.br I E-ISSN 1808-2599

Revista da Associação Nacional dos Programas de Pós-Graduação em Comunicação. Brasília, v.11, n.2, maio/ago. 2008

A identificação das edições, a partir de 2008 passa a ser volume anual com três números.

\section{CONSELHO EDITORIAL}

\section{Afonso Albuquerque}

Universidade Federal Fluminense, Brasil

Alberto Carlos Augusto Klein

Universidade Estadual de Londrina, Brasi

Alex Fernando Teixeira Primo

Universidade Federal do Rio Grande do Sul, Brasi

Alfredo Vizeu

Universidade Federal de Pernambuco, Brasil

Ana Carolina Damboriarena Escosteguy

Pontifícia Universidade Católica do Rio Grande do Sul, Brasil

Ana Silvia Lopes Davi Médola

Universidade Estadual Paulista, Brasil

André Luiz Martins Lemos

Universidade Federal da Bahia, Brasil

Ângela Freire Prysthon

Universidade Federal de Pernambuco, Brasil

Antônio Fausto Neto

Universidade do Vale do Rio dos Sinos, Brasil

Antonio Carlos Hohlfeldt

Pontifícia Universidade Católica do Rio Grande do Sul, Brasil

Arlindo Ribeiro Machado

Universidade de São Paulo, Brasil

César Geraldo Guimarães

Universidade Federal de Minas Gerais, Brasi

Cristiane Freitas Gutfreind

Pontifícia Universidade Católica do Rio Grande do Sul, Brasil

Denilson Lopes

Universidade Federal do Rio de Janeiro, Brasil

Eduardo Peñuela Cañizal

Universidade Paulista, Brasil

Erick Felinto de Oliveira

Universidade do Estado do Rio de Janeiro, Brasil

Francisco Menezes Martins

Universidade Tuiuti do Paraná, Brasil

Gelson Santana

Universidade Anhembi/Morumbi, Brasil

Hector Ospina

Universidad de Manizales, Colômbia

leda Tucherman

Universidade Federal do Rio de Janeiro, Brasil

Itania Maria Mota Gomes

Universidade Federal da Bahia, Brasil

Janice Caiafa

Universidade Federal do Rio de Janeiro, Brasil

Jeder Silveira Janotti Junior

Universidade Federal da Bahia, Brasil
John DH Downing

University of Texas at Austin, Estados Unidos

José Luiz Aidar Prado

Pontifícia Universidade Católica de São Paulo, Brasil

José Luiz Warren Jardim Gomes Braga

Universidade do Vale do Rio dos Sinos, Brasi

Juremir Machado da Silva

Pontifícia Universidade Católica do Rio Grande do Sul, Brasil

Lorraine Leu

University of Bristol, Grã-Bretanha

Luiz Claudio Martino

Universidade de Brasília, Brasil

Maria Immacolata Vassallo de Lopes

Universidade de São Paulo, Brasil

Maria Lucia Santaella

Pontifícia Universidade Católica de São Paulo, Brasil

Mauro Pereira Porto

Tulane University, Estados Unidos

Muniz Sodre de Araujo Cabral

Universidade Federal do Rio de Janeiro, Brasil

Nilda Aparecida Jacks

Universidade Federal do Rio Grande do Sul, Brasil

Paulo Roberto Gibaldi Vaz

Universidade Federal do Rio de Janeiro, Brasil

Renato Cordeiro Gomes

Pontifícia Universidade Católica do Rio de Janeiro, Brasil

Ronaldo George Helal

Universidade do Estado do Rio de Janeiro, Brasil

Rosana de Lima Soares

Universidade de São Paulo, Brasil

Rossana Reguillo

Instituto Tecnológico y de Estudios Superiores do Occidente, México

Rousiley Celi Moreira Maia

Universidade Federal de Minas Gerais, Brasil

Sebastião Carlos de Morais Squirra

Universidade Metodista de São Paulo, Brasil

Simone Maria Andrade Pereira de Sá

Universidade Federal Fluminense, Brasil

Suzete Venturelli

Universidade de Brasília, Brasil

Valério Cruz Brittos

Universidade do Vale do Rio dos Sinos, Brasil

Veneza Mayora Ronsini

Universidade Federal de Santa Maria, Brasil

Vera Regina Veiga França

Universidade Federal de Minas Gerais, Brasil

\section{COMISSÃO EDITORIAL}

Ana Gruszynski I Universidade Federal do Rio Grande do Sul, Brasil João Freire Filho I Universidade Federal do Rio de Janeiro, Brasil Rose Melo Rocha I Escola Superior de Propaganda e Marketing, Brasil

\section{CONSULTORES AD HOC}

Aníbal Bragança I Universidade Federal Fluminense, Brasil Gisela Castro I Escola Superior de Propaganda e Marketing, Brasil

Gislene Silva I Universidade Federal de Santa Catarina, Brasil

Maria Helena Weber I Universidade Federal do Rio Grande do Sul, Brasil

Rosana de Lima Soares I Universidade de São Paulo, Brasil

Tania Hoff I Escola Superior de Propaganda e Marketing, Brasil

REVISÃO DE TEXTO E TRADUÇÃo I Everton Cardoso

ASSISTÊNCIA EDITORIAL E EDITORAÇÃO ELETRÔNICA I Raquel Castedo
COMPÓS I www.compos.org.br

Associação Nacional dos Programas de Pós-Graduação em Comunicação

Presidente

Erick Felinto de Oliveira

Universidade do Estado do Rio de Janeiro, Brasil erickfelinto@uol.com.br

Vice-presidente

Ana Silvia Lopes Davi Médola

Universidade Estadual Paulista, Brasil

asilvia@faac.unesp.br

Secretária-Geral

Denize Correa Araújo

Universidade Tuiuti do Paraná, Brasil

denizearaujo@hotmail.com 